\title{
ON RAILROAD TANK CAR PUNCTURE PERFORMANCE: PART II - ESTIMATING METRICS
}

\author{
David Y. Jeong \\ Michael E. Carolan \\ Benjamin Perlman \\ Volpe National Transportation Systems Center \\ US Department of Transportation \\ Cambridge, Massachusetts, USA
}

\section{ABSTRACT}

This paper is the second in a two-part series on the puncture performance of railroad tank cars carrying hazardous materials in the event of an accident. Various metrics are often mentioned in the open literature to characterize the structural performance of tank cars under accident loading conditions. One of the consequences in terms of structural damage to the tank during accidents is puncture. This two-part series of papers focuses on four metrics to quantify the performance of tank cars against the threat of puncture: (1) speed, (2) force, (3) energy, and (4) conditional probability of release.

In Part I, generalized tank car impact scenarios were illustrated. Particular focus is given to the generalized shell impact scenario because performance-based requirements for shell puncture resistance are being considered by the regulatory agencies in United States and Canada. Definitions for the four performance metrics were given. Physical and mathematical relationships among these metrics were outlined. Strengths and limitations of these performance metrics were discussed.

In this paper (Part II), the multi-disciplinary approach to develop engineering tools to estimate the performance metrics is described. The complementary connection between testing and modeling is emphasized. Puncture performance metrics, which were estimated from other sources, are compared for different tank car designs. These comparisons are presented to interpret the metrics from a probabilistic point of view. In addition, sensitivity of the metrics to the operational and design factors is examined qualitatively.
\end{abstract}

\section{INTRODUCTION}

This two-part series of papers concentrates on the metrics to quantify the performance of railroad tank cars in terms of their structural capability to resist puncture from an impacting object. Generalized scenarios for head and side (or shell) impacts on tank cars were presented in Part I. Federal regulations were instituted in the 1980s to require head shields for railroad tank cars carrying certain classes of hazardous materials [1]. Recently, new regulations were issued to require head shields for railroad tank cars carrying high-hazard flammable liquids which include crude oil and ethanol [2]. Performance-based requirements for shell puncture are being considered by the regulatory agencies in the United States and Canada. The generalized shell impact scenario shown in Figure 1 has been conceived to standardize comparative performance of different tank car designs against the threat of shell puncture. The following characteristics were taken into consideration during the development of the test setup for the generalized shell impact scenario: safety, controllability, repeatability, and amenability to analysis. Since standards and regulations for shell puncture do not yet exist, this two-part series of papers have given particular attention to shell puncture.

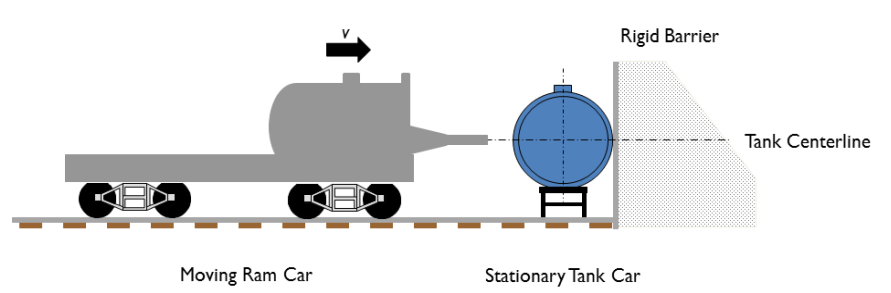

Figure 1: Generalized Shell Impact Scenario 
Part I also introduced definitions for four different puncture performance metrics: (1) threshold puncture speed for a given collision scenario, (2) peak impact force for a given collision scenario, (3) puncture energy for a given collision scenario, and (4) the probability of lading loss by puncture in the event of an accident, or conditional probability of release (CPR). Here, puncture was defined as any tears, holes, cracks, or perforations in the tank material that would allow the commodity to escape. The physical and mathematical relationships among these metrics were also discussed in Part I.

In this paper (Part II), the application of various methods, approaches, and disciplines to develop engineering tools to estimate the performance metrics are described. In addition, numerical studies are conducted to compare the puncture performance metrics for different railroad tank car designs. The relative effect of different operational and design factors on the likelihood of puncture is examined qualitatively. Moreover, information presented in both papers is intended to help in the development of rational guidelines to improve the safety performance of railroad tank cars carrying hazardous materials.

\section{ANALYTICS TO ESTIMATE METRICS}

Analytics is defined as the method of logical analysis [3]. Analytics relies on the simultaneous application of several disciplines such as mathematics, statistics, modeling, simulation, operations research, and risk analysis. Modeling and simulation are based on physics and basic engineering principles. Several business sectors now employ analytics to process information to provide insights into better decision- making. The term "analytics" has not yet been formally used to estimate or quantify performance of railroad tank cars under accident loading conditions. However, the multi-disciplinary approach and the various processes used in analytics are entirely applicable for the present purpose.

The tools used to estimate the performance metrics for railroad tank cars under accident or extreme loading conditions may be divided into three groups: (1) structural analyses, (2) physical testing, and (3) statistical analyses. Structural analyses refer to the development, verification, and validation of analytical and computational models to examine and simulate the response of the tank car structure to impacting forces. Specifically finite element methods have been used to carry out tank car structural analysis. Physical testing means the conduct of experiments to examine material properties (e.g. yield and ultimate tensile strength), geometric effects (e.g. effect of tank thickness), and other factors. Statistical analyses refer to the collection and analysis of accident data to understand damage to tank cars and their failure modes. Statistical methods are also used to analyze and organize data from physical tests.

Table 1 provides a brief summary of the relative strengths and limitations of these three disciplines. Moreover, the three disciplines are not mutually exclusive. As shown schematically in Figure 2, testing and modeling are complementary efforts that are required to provide confidence and credibility to results from analytics. The various testing and modeling techniques that are used in the building-block approach to develop engineering tools for analytics are described as follows.

Table 1: Relative Strengths and Limitations of Various Disciplines

\begin{tabular}{|l|l|l|}
\hline Discipline & \multicolumn{1}{|c|}{ Relative Strengths } & \multicolumn{1}{c|}{ Relative Limitations } \\
\hline Structural Analyses & $\bullet \begin{array}{l}\text { Structural analyses are based on physics } \\
\text { and basic engineering principles. } \\
\text { Validated models can be used to examine } \\
\text { a wide range of conditions. }\end{array}$ & $\begin{array}{l}\bullet \\
\text { Level of effort to develop accurate and } \\
\text { credible models can be intensive. } \\
\text { Physical testing is required for validation. }\end{array}$ \\
\hline Physical Testing & $\bullet \begin{array}{l}\text { Results from well-conducted tests can } \\
\text { provide data to understand structural } \\
\text { behavior and the mechanics of failure. }\end{array}$ & $\bullet \begin{array}{l}\text { Testing is expensive. } \\
\text { Tests are conducted under a fixed set of } \\
\text { conditions, and cannot be performed for } \\
\text { every conceivable condition. }\end{array}$ \\
\hline Statistical Analyses & $\bullet \begin{array}{l}\text { Statistical analysis provides a link to } \\
\text { accident data and conditional probability } \\
\text { of release, which in turn is amenable to } \\
\text { cost-benefit and risk assessments. }\end{array}$ & $\begin{array}{l}\text { Structural response and mechanics of } \\
\text { failure cannot be understood from } \\
\text { statistics alone. } \\
\text { Data depend on accident conditions which } \\
\text { are uncontrolled and may not be } \\
\text { thoroughly documented. }\end{array}$ \\
\hline
\end{tabular}




\section{Physical Testing}

Referring to Figure 2, physical testing may be conducted at the small-scale or coupon level, component level, or full-scale level. The costs to carry out these tests increase as the level rises. As the expense increases and the level rises on the building-block pyramid, the physical tests become more complex but more representative of actual accident conditions.

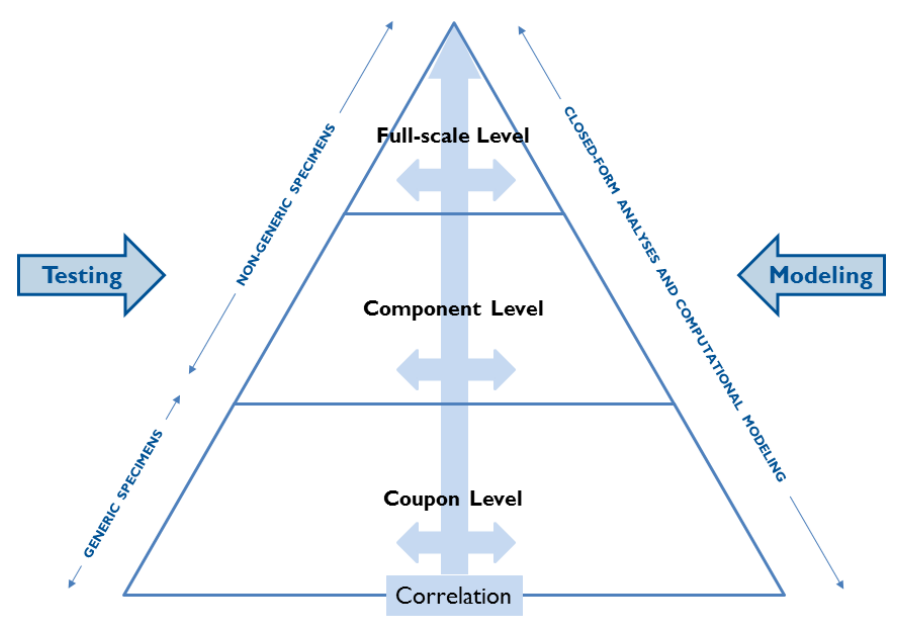

Figure 2: Building Block Approach to Testing and Modeling

In the coupon level, standardized tests may be performed to characterize basic material properties such as yield strength, ultimate tensile strength, and elongation. An extensive laboratory testing program was conducted to examine the material properties of steel samples obtained from tank cars that were retired from the fleet [4]. This program also included fracture toughness testing using standard Charpy V-notch and compact tension specimens.

Testing at the component level may employ unique and non-standard testing procedures. For example, an oversized pendulum impactor, called the Bulk Fracture Charpy Machine (BFCM), was constructed to study the fracture behavior of various tank car steels. The effect of various factors (such as specimen thickness and striker type) on impact energy was demonstrated through tests and analysis [5]. Moreover, the testing and modeling for the BFCM provided a benchmark to apply failure criteria to model puncture in finite element analyses of full-scale shell impacts [6].

Testing at the full-scale level has been conducted using retired tank cars under the generalized shell impact scenario shown schematically in Figure 1. To date, six full-scale shell impact tests have been conducted and sponsored by the Federal Railroad Administration (FRA). An overview of these tests was provided in Part I.

\section{Computational Models}

The right-hand side of the building-block pyramid shown in Figure 2 shows that modeling complements the testing effort. As the level of complexity rises on the schematic pyramid, modeling becomes more reliant on numerical or computational methods such as finite element analysis (FEA). Moreover, data collected from physical tests are used to confirm and validate the results from the finite element analyses. Research sponsored by the FRA and specific to FEA modeling on the structural integrity of railroad tank cars can be found in References 6 through 10.

Finite element analysis incorporates the following aspects of the shell impact scenario: (1) structural dynamics, (2) fluidstructure interaction, (3) non-linear material behavior, and (4) material failure.

Structural dynamics refers to movement of the structure with respect to time under prescribed loading. Explicit finite element analysis is generally used to model and simulate structures involved with large deformations with time dependency such as crashes, blasts and impacts. This aspect of FEA for tank car impacts is similar to that used to model or simulate automobile crashes.

Fluid-structure interaction (FSI) refers to the forces exerted by the fluid lading and the tank on each other, and their relative motions. The fluid lading has the following dynamic effects on the structural behavior of a closed container during impact: additional mass or weight of the fluid, increased stiffness to the structure due to fluid pressure, and variation of pressure as the structure deforms. Most engineering problems involving FSI require numerical simulations to model because closed-form or analytical solutions are extremely difficult, if not impossible, to obtain. The numerical methods to model FSI may be separated into two categories: monolithic versus partitioned approaches [11]. In the monolithic approach, the fluid and the structure are treated similarly in the mathematical formulations of the model. In contrast, the partitioned approach treats the fluid and the structure separately. Another aspect in modeling FSI is the treatment of meshes, which may be classified as conforming mesh methods and non-conforming mesh methods [11]. In conforming methods, the FEA grid or mesh must be updated for each time step. In non-conforming methods, mesh updating is not required. Additional techniques can be used to model the solid, liquid, and gases phases of each material, as appropriate.

Nonlinear material behavior is characterized by elasticplastic constitutive (i.e. stress-strain) relations as well as large elastic-plastic deformations. Explicit finite element analysis is also well-suited for non-linear problems involving large-scale plasticity. Railroad tank cars are constructed with steel, whereas aluminum is a principal material in automobiles today.

Material failure refers to the implementation of theories and criteria in FEA to determine the point at which puncture of the tank occurs. Theories may be based on theoretical damage mechanics or may be phenomenological. Criteria for failure by puncture may be based on stress, strain, or a combination (e.g. 
strain energy). While the stress-strain behavior of metals such as steel and aluminum is well documented, failure theories such as ductile fracture are evolving.

One of the key outputs from computational modeling to examine the structural response of railroad tank cars under extreme or accident loading conditions is the force-indentation characteristic. Figure 3 compares the characteristic calculated from FEA [9] with processed test data in which the outcome of the full-scale test (and the modeling simulation) was puncture of the tank. The full-scale test and FEA analyses pertain to the following fixed conditions: DOT105J500W (i.e. jacketed, chlorine tank car); impact speed of 15.1 miles per hour ( $\mathrm{mph}$ ); 6 -inch by 6 -inch indenter with rounded edges $1 / 2$-inch radii; ram car weight of $286,000 \mathrm{lb}$; internal pressure of $100 \mathrm{psi}$, and $10.6 \%$ outage (tank contained clay slurry). Two results from FEA are shown in which fluid-structure interaction (FSI) is modeled in two different ways. Multi-phase means that the solid, liquid, and gas phases of the constituents are modeled explicitly. In the simplified approach, the gas phase is omitted, and the fluid pressure is replaced with a prescribed, constant pressure on the inner wall of the commodity-carrying tank. The FEA results from both methods are within reasonable agreement with the test data but the simplified approach underestimates the peak force and the impactor displacement at puncture. The discrepancies between the FEA and the test are bracketed by the shaded region in the figure, which may be considered as the threshold zone or region in which puncture may be expected to occur.

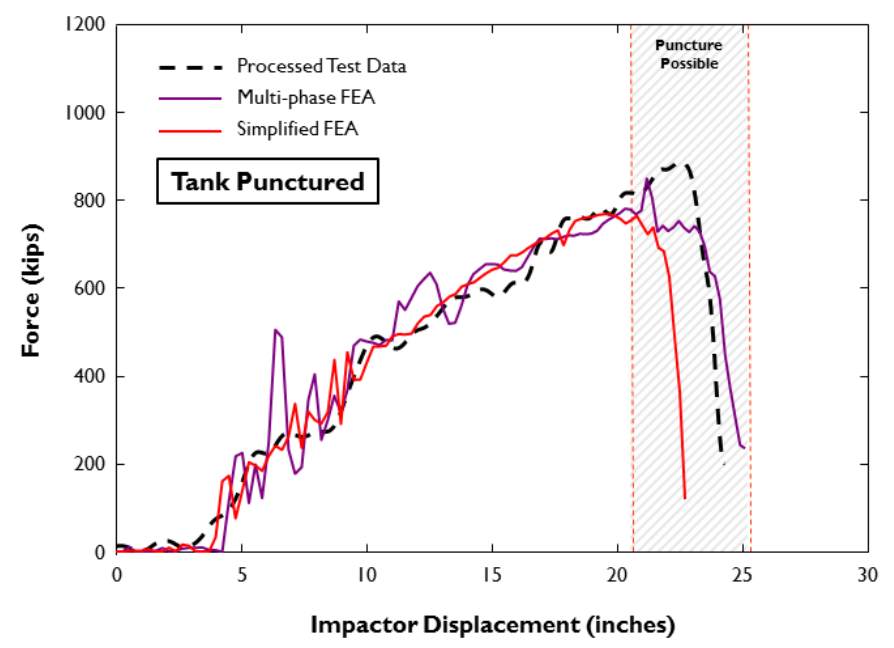
Figure 3: Comparison Between Full-scale Shell Impact Test
Data and Finite Element Analyses [9]

The comparison between the two methods to model FSI in Figure 3 requires careful interpretation. As will be discussed later in this paper, some of the fixed conditions pertaining to the test and FEA results may interact with each other. In this case, the effect of FSI may have been diminished by the 6-inch by 6- inch indenter. Repeating the testing and/or analysis for a larger (e.g. 12-inch by 12-inch) indenter, for instance, could provide more insight regarding the interplay of FSI with indenter size, outage, and internal pressure.

\section{Mathematical Models}

Mathematical models for railroad tank car puncture include semi-empirical methods for head impacts [12-15] and semianalytical methods for shell impacts [16]. In the semi-empirical methods, the mathematical equations were based on curvefitting of head impact test data. In the semi-analytical methods, curve-fitting was based on regressions on results from finite element analyses conducted at that time. In these two methods, the mathematical models estimate the threshold puncture speed for head and shell impacts respectively.

In research sponsored by Railway Supply Institute and the Association of American Railroads, a semi-empirical model was developed to estimate the threshold puncture speed for railroad tank cars in head impacts [12]. The model was later modified to account for the effects of jackets and head shields [13]. Correlations with data from physical tests [14] and with results from engineering analyses [15] indicate that the semi-empirical method to predict puncture speeds gives reasonable but conservative estimates. Here conservative means that the calculated puncture speed is a lower-bound estimate of the threshold speed. In other words, the actual or true puncture speed is most likely to be somewhat higher than the value calculated by the semi-empirical method.

In research sponsored by The Chlorine Institute, a mathematical model was developed to estimate the probability of lading loss, or conditional probability of release (CPR), for head and shell impacts [17-18]. The model assumes that a single driving-force parameter, called the puncture intensity, can be used to normalize all collision scenarios. In this formulation, puncture intensity is non-dimensional, and is assumed to be proportional to impact energy. Furthermore, impact energy is assumed to follow a Weibull probability distribution, which captures the probabilistic nature of puncture.

The results from the puncture intensity model are calibrated to match the CPR estimates from Reference [19]. Therefore, the mathematical equations comprising the puncture intensity model may be considered as novel and expedient curve fits. Figure 4 compares results from the puncture intensity model to the shaded areas representing the 95 percent confidence intervals for jacketed and non-jacketed cars from Treichel et al. [19] for shell losses. Results for jacketed cars are represented by open square symbols, and those for and non-jacketed cars are denoted by open circles. The nominal jacket thickness is assumed to be 11-gage or 0.119 inch. Later in this paper, the puncture intensity model will be used to extrapolate estimates of CPR for tank cars with jacket thicknesses greater than the nominal thickness. 


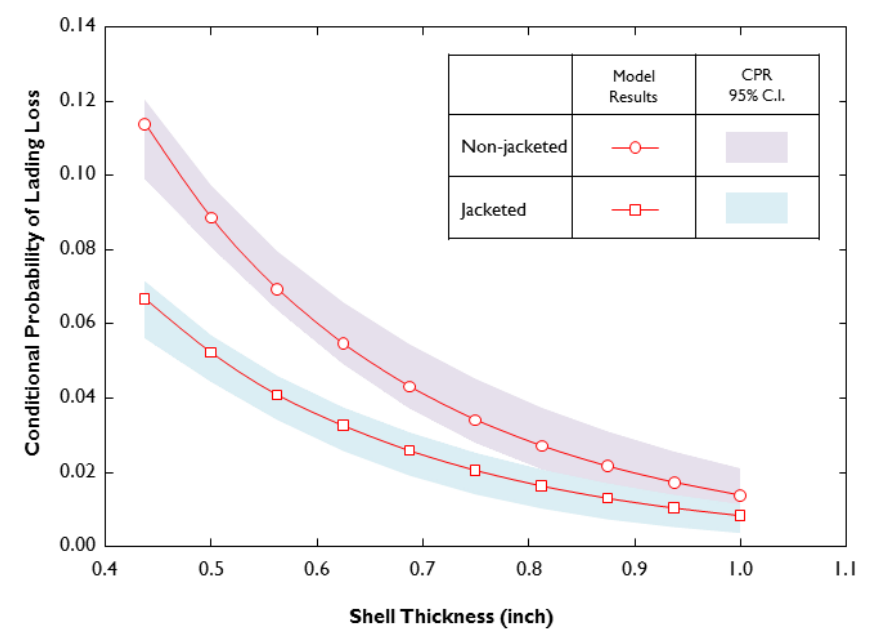

Figure 4: Results from Puncture Intensity Model and CPR Estimates for Shell Losses

\section{Probabilistic Methods}

The use of probabilistic methods to examine structural behavior under impact conditions is a reasonable approach since no two accidents are identical. For example, factors characterizing accident severity (e.g. train speed, impactor shape and size, and impact mass) and material properties can vary from one accident to another or even within a given accident. In addition, randomness and uncertainty in these factors can be taken into account through probabilistic analysis.

A probabilistic approach using Monte Carlo techniques [20] has been employed to examine the relationship between puncture energy and conditional probability of release (CPR) for head impacts. Figure 5 shows a schematic of the probabilistic analysis to estimate CPR. The factors considered in the analysis are treated as random variables, which are characterized by an assumed probability density function with a mean (or average) value and a variance (or standard deviation). The factors contributing to accident loading are assumed to be effective collision mass and impact speed. Other factors that are assumed to affect puncture resistance are: tank diameter, indenter size, ultimate strength of the tank material, and tank thickness. In the probabilistic analysis [20], a semi-empirical equation, originally developed for puncture of pipelines during excavation [21], is used to calculate puncture resistance as a function of these factors. The schematic also shows the probability density functions assumed for each of these six factors. Monte Carlo methods are used to generate random sampling for the various factors based on the assumed probability density functions. The overlap in the tail ends of the distributions for accident loading and puncture resistance represents the number of accidents resulting in lading loss.

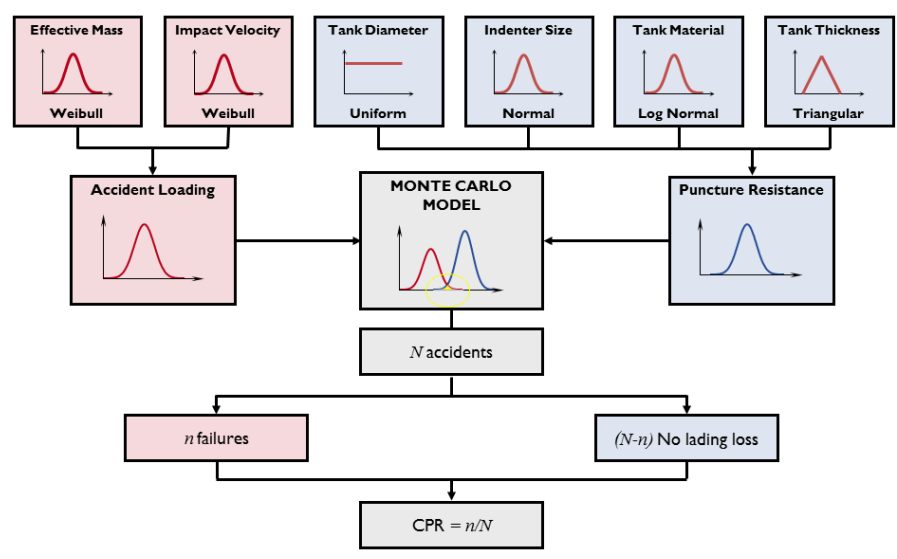

Figure 5: Schematic of Monte Carlo Analysis for CPR

The Monte Carlo analysis described in Reference [20] for head impacts was resurrected in this paper to examine shell impacts. Figure 6 compares results for conditional probability of release for shell losses from the probabilistic approach with those based on the logistic regression analysis [19], which was described in Part I. The symbols (solid circles for non-jacketed cars and solid squares for jacketed cars) are the results from the Monte Carlo method. The shaded areas in the figure represent the 95 percent confidence intervals, which were derived in [19]. These results were back-calculated by varying the mean values and variances (i.e. standard deviations) for the assumed probability density functions, and iterating until the results were kept within the 95 percent confidence bands for both sets of data (i.e. jacketed and non-jacketed tanks).

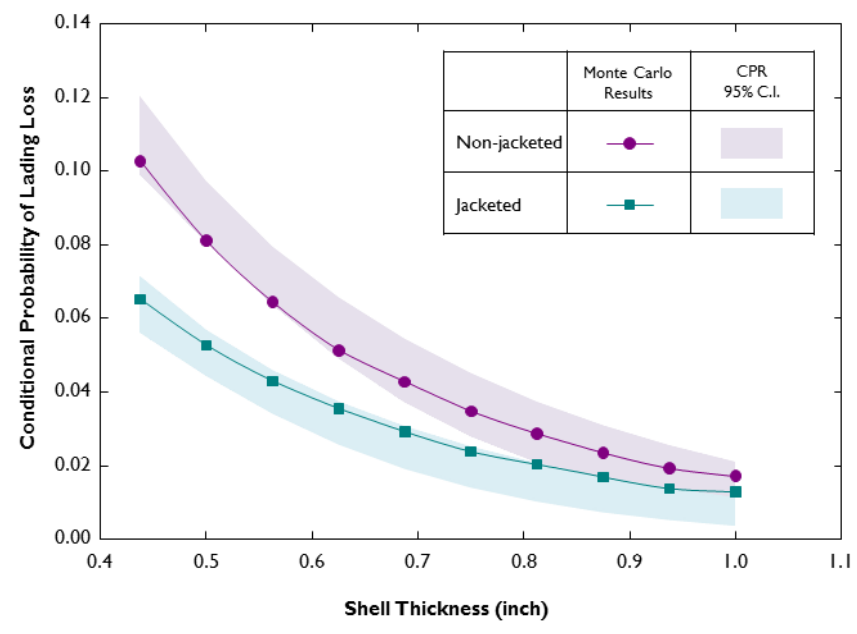

Figure 6: Results from Monte Carlo Analysis and CPR Estimates for Shell Losses 
The objective of the probabilistic analysis [20] was to use the calibrated model for sensitivity studies to examine the relative effect of these factors on the conditional probability of release. Results from the sensitivity studies indicated that the most significant factors affecting conditional probability of release are: impact velocity, effective collision mass, and indenter size. However, none of these three factors are taken into account in the logistic regression analysis. A by-product of the probabilistic analysis is an estimation of the probability distributions for the various factors. But these back-calculated probability distributions are difficult to corroborate because these three factors are often unknown and therefore are not thoroughly documented in accident reports.

\section{Treatment of Uncertainties}

Understanding uncertainties (e.g. inherent randomness, modeling difficulties, and statistical variation) is helpful to establish confidence and credibility in the results from analytics. In structural reliability analysis, it is commonly accepted that uncertainties should be interpreted and differentiated in regard to their type and origin [22]. Aleatory or irreducible uncertainties are inherent variations. Epistemic or reducible uncertainties are deficiencies from lack of knowledge. An example of aleatory uncertainty is the characterization of mechanical properties of steel. Yield strength, for instance, follows a probability distribution (e.g. normal or log-normal). The distribution can be defined by collecting data from physical testing but the variation in properties cannot be completely eliminated. The functional form of the force-indentation characteristic may serve as an example of an epistemic uncertainty. Prior to conducting any physical tests or performing any analysis, it would have been logical to assume that the force-indentation characteristic is monotonic and nonlinear. Results from physical testing and computational modeling confirm the initial assumptions and, further, quantify the degree of nonlinearity.

The example used to describe epistemic uncertainty also illustrates the time dependency of knowledge (Figure 7). In theory, a given phenomenon is perfectly known if the observations are errorless. Modeling or simulating the same phenomenon to predict future behavior will be imperfect because of modeling and statistical uncertainties. Forecasts and predictions become less certain as the time horizon is extended further into the future.

Moreover, any prevailing uncertainty, whichever type or whatever the source, should be taken into account in the process of the analytics. In general, uncertainties can be managed by constantly updating information. For example, accident databases must be constantly updated to include the most recent observations and information. These databases may also need to be re-organized or re-structured to reflect changes in operational practice, safety design features, and regulatory requirements. Modeling difficulties and uncertainties may be addressed by improvements in state-of-the-art techniques which continue to evolve for complex engineering problems such as fluid-structure interaction, blasts, impacts, and penetrations.

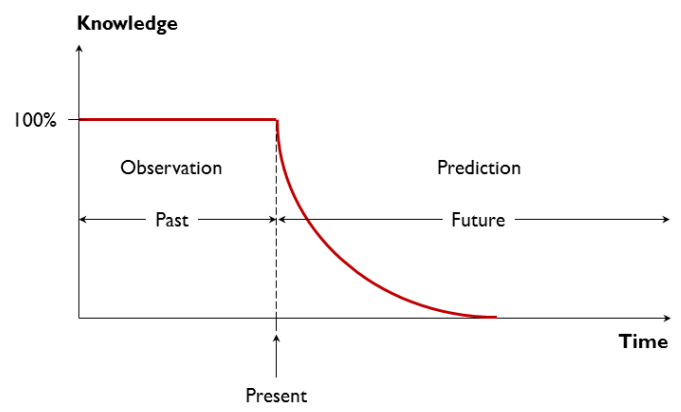

Figure 7: Schematic to Illustrate Time Dependence of Knowledge [22]

\section{COMPARISON OF PERFORMANCE METRICS}

This section presents results from numerical experiments to compare the performance metrics for different tank car designs. Estimates of the puncture performance metrics are extracted from previously conducted studies. For example, energy and force metrics originate from finite element results published in Reference [10]. Speed is derived directly from energy, assuming a nominal ram-car weight. Numerical values for CPR can be found in Treichel et al. [19].

Table 2 summarizes the shell characteristics for six different tank car configurations or designs, which form the basis for these numerical experiments. The baseline case corresponds to a non-jacketed DOT111A100W specification tank car, which is also known as the general-purpose tank car. In Case 1, the grade of steel is considered as an improvement above the baseline because the strength properties for TC128-B are slightly higher than those for A516-70. In Case 2, shell thickness is increased and the grade of steel is improved above the baseline. In Case 3, a jacket (with 11-gage thickness) is incorporated into the baseline design. Case 4 describes the design with the thickest shell. In Case 5, the combined shell and jacket thickness (i.e. sum of the two thicknesses) is equal to the shell thickness (without a jacket) in Case 4.

Table 2: Shell Characteristics for Different Tank Cars

\begin{tabular}{|c|c|c|c|c|}
\hline \multirow{2}{*}{ Case } & \multicolumn{2}{|c|}{ Shell } & \multicolumn{2}{c|}{ Jacket } \\
\cline { 2 - 5 } & $\begin{array}{c}\text { Thickness } \\
\text { (inch) }\end{array}$ & Material & $\begin{array}{c}\text { Thickness } \\
\text { (inch) }\end{array}$ & Material \\
\hline Baseline & $7 / 16$ & A5I6-70 & None & - \\
\hline I & $7 / 16$ & TCI 28-B & None & - \\
\hline 2 & $1 / 2$ & TCI28-B & None & - \\
\hline 3 & $7 / 16$ & A5I6-70 & 0.1196 & Al0II \\
\hline 4 & $5 / 8$ & TCI28-B & None & - \\
\hline 5 & $3 / 8$ & TCI28-B & $1 / 4$ & TC-I28B \\
\hline
\end{tabular}


Figure 8 shows results of shell puncture energies gleaned from finite element analyses [10] for a 12-inch by 12-inch indenter. The error bars for shell puncture energy correspond to \pm 10 percent variation from the estimated puncture energy for a given case. The figure also shows the percent improvement for each of the five cases compared to the baseline. The case numbers are arranged in order of increasing improvement in terms of shell puncture energy or resistance to puncture from side or shell impacts above the baseline. The combined thickness (i.e. addition of shell and jacket thicknesses) in Case 5 is equal to the shell thickness alone (without a jacket) in Case 4, yet the estimated puncture energy in Case 5 is higher than that in Case 4. A physical explanation for the improved puncture resistance in Case 5 might be that the jacket blunts the impact load, distributing the load over a larger area than the 12 -inch by 12-inch footprint of the indenter.

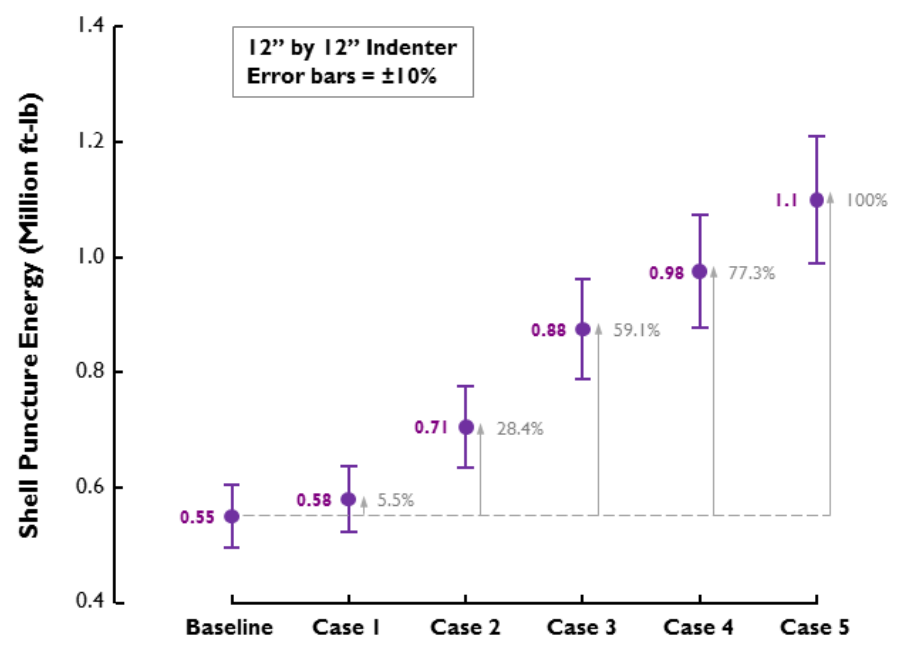

\section{Figure 8: Estimated Shell Puncture Energies for Different Tank Cars}

Figure 9 shows the threshold puncture speeds for each case, which were derived directly from the puncture energies shown in the previous figure assuming a ram car weight of 286 kips. The error bars in this plot correspond to the \pm 5 percent variation in puncture energy, which translates roughly to speed variation of \pm 0.4 to $\pm 0.5 \mathrm{mph}$. Because puncture speed is directly proportional to the square root of the puncture energy, the corresponding percent variation in puncture speed will always be less than the percent variation in puncture energy. The numerical values of the threshold puncture speed appear to be relatively low when compared to typical train derailment speeds, but are indicative of the severe nature of the generalized shell impact scenario because the tank car is braced against a concrete wall. The relationship between impact speed in the generalized shell scenario and the train speed at the time of derailment was discussed in Part I.

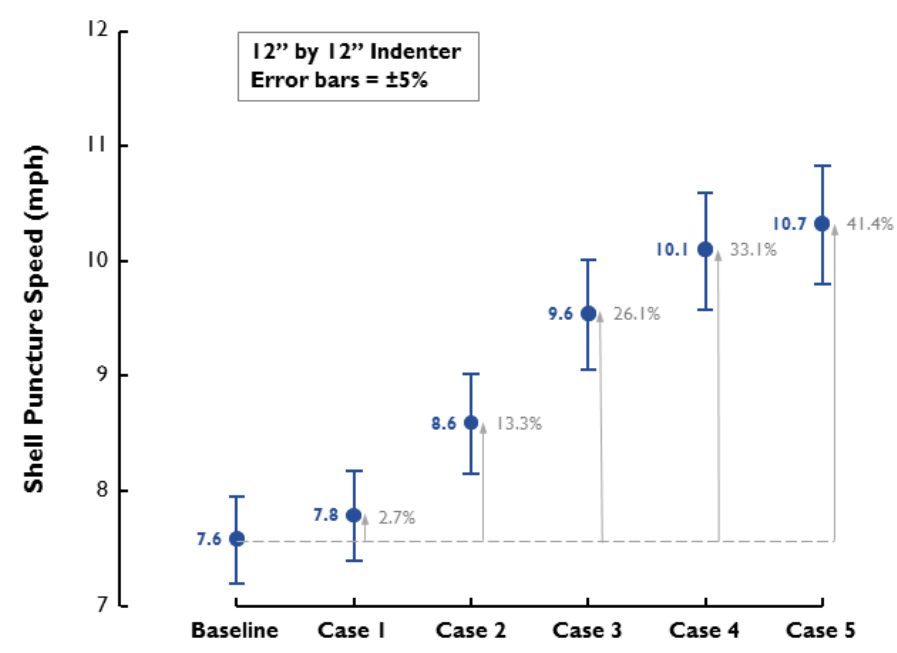
Figure 9: Estimated Shell Puncture Speeds for Different
Tank Cars

Puncture force estimates for the different tank car designs were also collected from finite element results [10], and are shown in Figure 10. These results are shown for a 12-inch by 12 -inch indenter. The error bars characterize a force variation of \pm 10 percent. In the previous metrics based on speed and energy, an incremental improvement in puncture performance was exhibited as the cases progressed, such that Case 1 had the lowest numerical value and Case 5 had the highest. When the performance metric is based on force, Case 4 exhibits the highest numerical value in Figure 10. In addition, the force metric suggests no difference in performance between Cases 2 and 3 , which was not indicated previously.

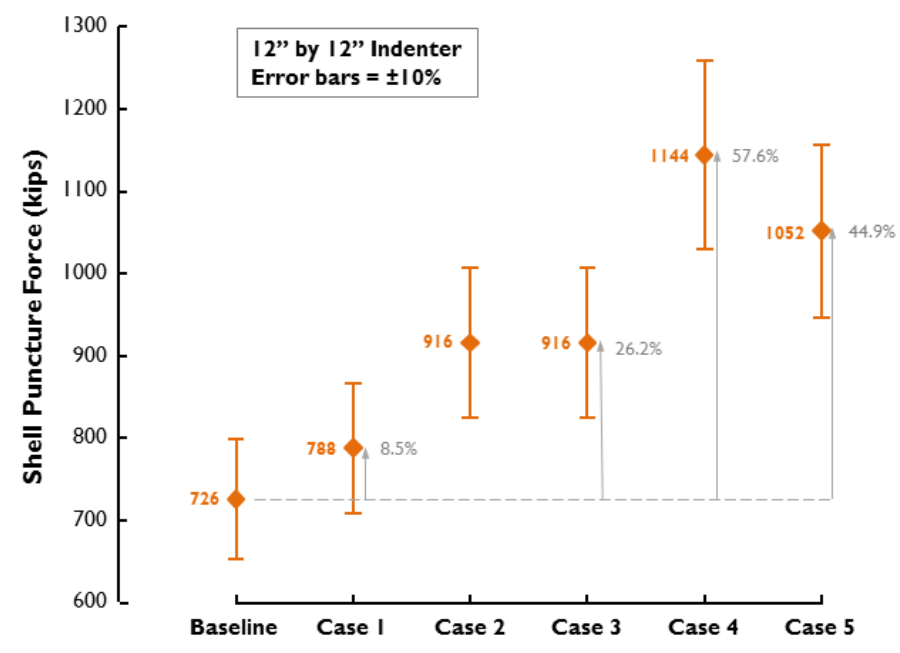

Figure 10: Estimated Shell Puncture Force for Different Tank Cars 
Figure 11 shows results for the probability of lading loss, or conditional probability of release, from the tank car shell. Whereas an increase in threshold energy, speed, and force signify improved puncture performance or resistance, a reduction in CPR means better puncture resistance when comparing two different tank car designs. The results shown in the figure were obtained from Treichel et al. [19] except for Case 5. The estimates for CPR in Case 5, which specifies a 1/4inch jacket, were calculated using the puncture intensity model developed by Anderson [17-18]. The error bars in this figure correspond to the 95 percent confidence interval. The figure shows that Case 5 has improved performance over Case 4 when $\mathrm{CPR}$ is used as a metric for puncture resistance.

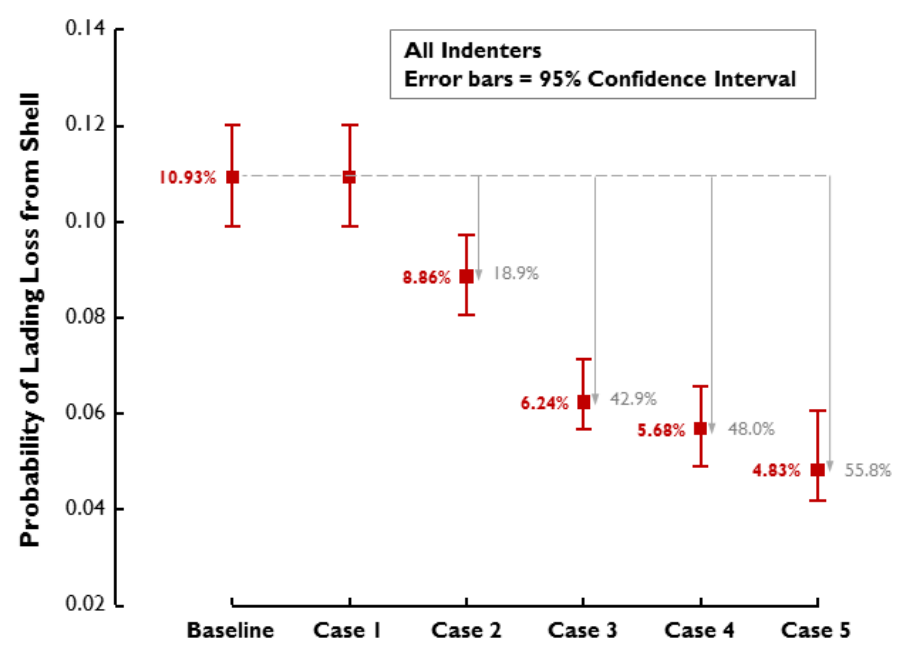

\section{Figure 11: Estimated Probabilities of Lading Loss from Shell for Different Tank Cars}

The metrics for puncture energy, speed, and force display a slight improvement in puncture resistance when the steel is upgraded from A516-70 to TC-128B (i.e. baseline versus Case 1). CPR is unable to distinguish any difference between grades of steel. However, the difference in performance between A516-70 and TC-128B as estimated by the other metrics is within the error bars for those metrics.

The puncture force metric is unable to distinguish any difference in performance between Cases 2 and 3. However, CPR clearly shows improved performance in Case 3 over Case 2. Threshold energy and speed also indicate that Case 3 has improved puncture performance relative to Case 2 .

CPR does not account explicitly for the effect of indenter size. Testing and analyses (finite element analysis and probabilistic analysis) have clearly demonstrated that puncture energy and puncture speed are strongly dependent on the size of the indenter. As the indenter size becomes smaller, differences in structural performance between different tank car designs become smaller, and could potentially become difficult to distinguish.
As discussed in Part I, the metrics based on energy, speed, and force are related through physics (i.e. mechanics principles of energy conservation and impulse-momentum). However, the relationship between these three metrics and conditional probability of release is not self-evident. An implied relationship can be constructed by cross-plotting the results for shell puncture energy from Figure 8, as an example, with the results for CPR for shell losses from Figure 11. The resultant cross-plot shown in Figure 12 includes horizontal error bars corresponding to \pm 10 percent variation in the estimated shell puncture energy for each case and vertical error bars corresponding to the 95 percent confidence interval for probability of lading loss for shell impacts. Dashed lines are drawn in the figure to represent the upper and lower bounds for the combination of these two puncture performance metrics. Qualitatively, the figure exhibits a nonlinear and inverse relationship between shell puncture energy and CPR. Quantitatively, the relationship should be interpreted with the caveat that the estimates for shell puncture energy apply only to a 12-inch by 12-inch indenter. Moreover, the error bars and the upper and lower bound curves are included in these figures to envision the performance metrics from a probabilistic point of view.

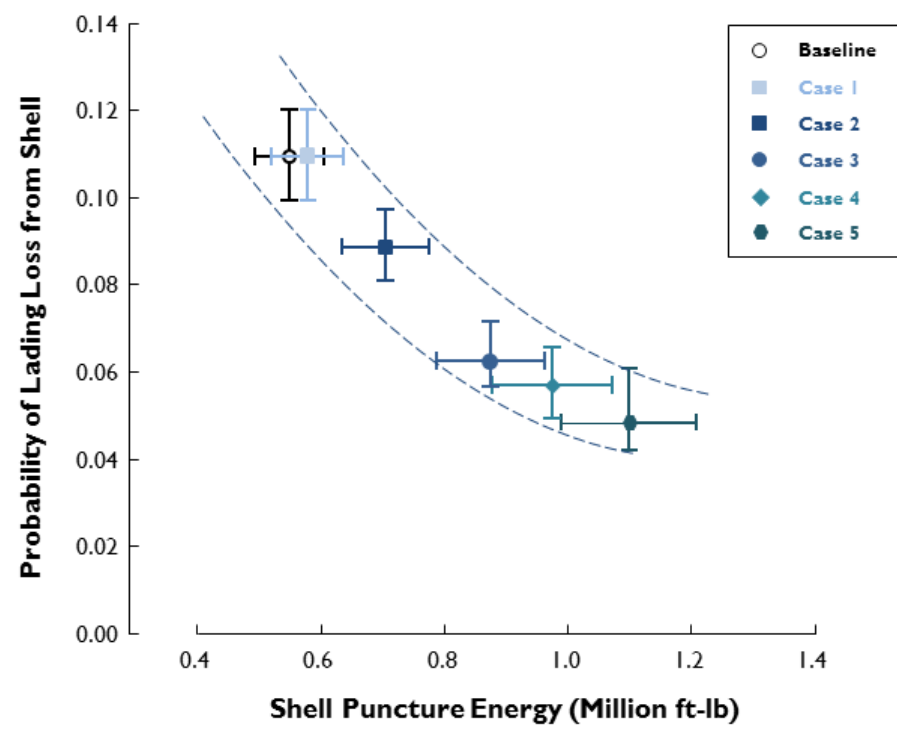

Figure 12: Conditional Probability of Release versus Shell Puncture Energy for Different Tank Cars

The puncture performance metrics presented here for energy and force were extracted from previously conducted finite element analyses [10]. The metrics were compared for the 12-inch by 12-inch indenter, but the primary objective of the previous FEA studies was to investigate puncture behavior of tank cars under a wide range of impact conditions. Moreover, the sizes and shapes of different impactors were examined in those studies, and were shown to play a significant role in puncture behavior. 


\section{DISCUSSION}

Physical testing and modeling are engineering tools that are needed by both Government and industry to assess and evaluate the performance of rail equipment. These tools have been discussed in the context of structural performance (specifically in terms of puncture resistance) of railroad tank cars designed to carry hazardous materials. The analytics described here are also applicable to the development of engineering tools to evaluate the thermal performance of tank cars (e.g. tank cars in a pool fire). Moreover, these engineering tools are used by the Government regulatory agencies to provide technical information that can be used to develop safety standards and regulations and to evaluate special permit applications. These tools are also used by the Government and industry to evaluate and forecast or predict the performance of new and innovative designs.

The development of credible models to simulate the structural behavior of tank cars under extreme loading conditions is one of the keys to analytics. The reasons for developing these models are: (1) to identify conditions for safety concern, (2) to provide guidance for physical testing, (3) to interpret data from the physical tests, (4) to extrapolate and predict behavior for conditions that may be difficult to conduct physical tests, and (5) to evaluate "what-if" scenarios.

Figure 13 is a flow diagram that illustrates how multidisciplinary analytics; specifically modeling, simulation, and physical testing; are used to develop engineering tools to evaluate performance. The flow diagram includes an iterative loop in which the activities are repeated until a desired result is achieved.

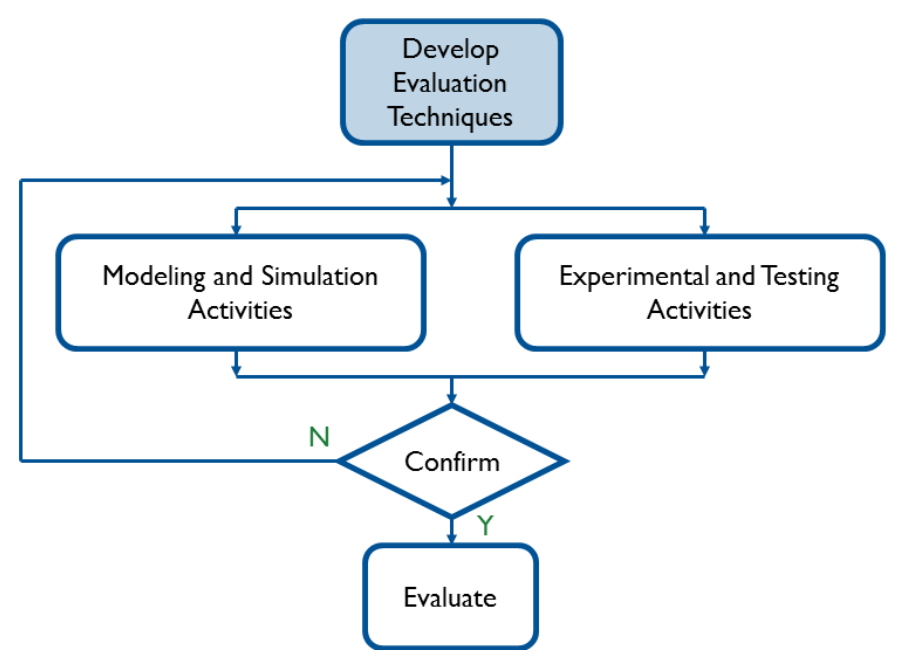

Figure 13: Flow Chart to Develop Evaluation Techniques
Based on the current state of modeling development, the relative effect of various factors affecting the likelihood of tank car shell puncture can be estimated qualitatively. For example, Figure 14 lists several factors and places them into two groups. "Correlated" means that as these factors (i.e., impact speed, ram car weight, and internal pressure) increase or become higher, the likelihood of puncture also increases. Conversely, "inversely correlated" means that as those factors increase (i.e. indenter size, outage, shell thickness, and tank diameter), improve (i.e. better material properties, higher grade of steel), or are incorporated into the design (such as a jacket), the likelihood of puncture decreases. The order in which these factors are listed indicates their relative significance in affecting the likelihood of puncture. For instance, impact speed and indenter size have the most significant or strongest effect on determining whether puncture will occur. Conversely, tank diameter has the weakest effect on the likelihood of puncture. Some factors may interact with others. For example, outage and internal pressure may interact when the volume of empty space becomes smaller as the tank deforms which may also increase the fluid pressure. The interplay between outage and internal pressure might also depend on the modeling technique for fluid-structure-interaction (FSI). In addition, indenter size may determine the role in which FSI plays. As indenter size becomes smaller, the effect of FSI may be less significant. The effect of outage on puncture resistance of general-purpose tank cars was preliminarily explored in previous research [10]. An asterisk is placed next to outage in Figure 14 to indicate that additional studies are needed to examine the interacting effects of outage with internal pressure, indenter size, and FSI modeling method. Finally, the relative effect and ranking of factors shown in Figure 14 apply specifically to the likelihood of shell puncture, and may be different for the likelihood of head puncture.

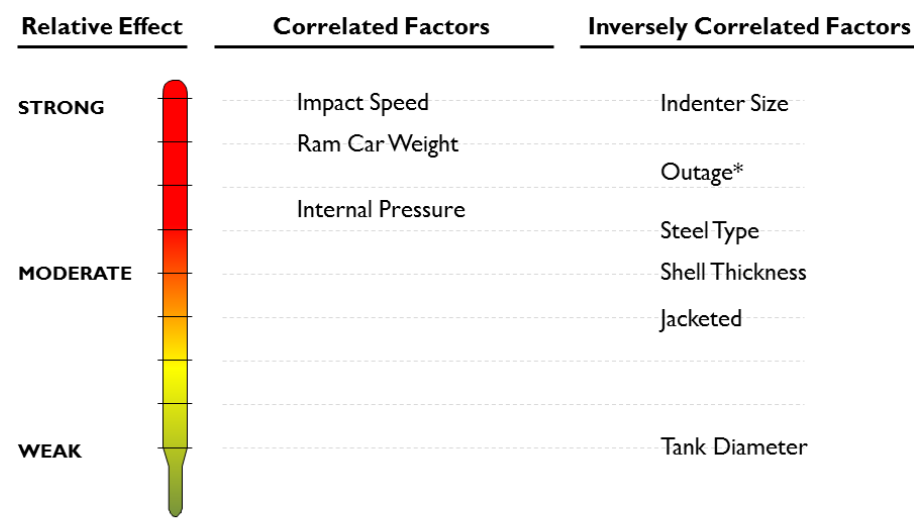

NOTE: Graphic is descriptive, and not intended to be quantitative

Figure 14: Relative Effect of Different Factors on Likelihood of Shell Puncture 


\section{CONCLUDING REMARKS}

This two-part series of papers described four different metrics to characterize the puncture resistance of different railroad tank car designs under shell impact: (1) threshold puncture speed, (2) peak impact force, (3) puncture energy, and (4) the probability of lading loss from the shell, also referred to as conditional probability of release (CPR). Each of these metrics is considered from a probabilistic viewpoint because the factors characterizing accident severity (e.g. load intensity, indenter size, effective collision mass, etc.) and puncture resistance (such as material properties related to failure) are fraught with uncertainties. In addition, the analytics used to estimate these metrics can only approximate reality.

Puncture performance metrics estimated by other sources [10 and 19] were used in this paper to provide a basis for numerical experiments in which the metrics were compared for different tank car designs. The comparisons provide useful insights. For example, all metrics are shown to be sensitive to shell thickness. Threshold puncture energy, speed, and force are sensitive to indenter size. All metrics clearly demonstrate the benefit of incorporating a jacket to improve shell puncture resistance. The physical explanation for the benefit is that the jacket blunts the impactor by distributing the load over a greater area than the actual size of the impactor. Depending on the performance metric, higher shell thickness and inclusion of a jacket can improve shell puncture resistance by 36 to 86 percent above the baseline, or DOT111A100W specification tank car. CPR is unable to discriminate the effects of indenter size and outage.

The previous studies were based upon state-of-the-art techniques and the available information at the time at which they were conducted. As discussed previously, uncertainties can be managed by continually updating in order to reflect the latest advances in state-of-the-art methods and the progression of the general knowledge base.

In the context of this paper, CPR is considered in terms of its use as a measure of a tank car's resistance to puncture in the event of an accident. As described in Part I of this two-part series of papers, CPR is a number that is calculated in a quantitative risk analysis. In such risk analysis, changing the tank car features to improve puncture resistance is one of the tactics that can be employed to mitigate the risk of accidental hazmat release. Other tactics to reduce this risk include: application of positive train control (PTC), implementation of electronically controlled pneumatic (ECP) brakes, and implementation and enforcement of new regulations to detect and remediate internal rail head defects. The impact of these tactics to reduce the number of train accidents leading to a hazmat release has been examined by Bing et al. [23]. One of the conclusions in that study is that broken rails originating from the development and growth of internal rail head defects are the leading cause of accidents involving hazmat release.

Practical use of analytics boils down to asking critical questions. In the development of performance-based standards for shell puncture, among these critical questions will be the specified indenter size and threshold puncture speed.

\section{ACKNOWLEDGMENTS}

The work described in this paper was sponsored by the Federal Railroad Administration (FRA), Office of Research and Development. Mr. Francisco González III is the FRA program manager for tank car and hazardous materials safety research. Mr. Kevin Kesler is the Chief of the Equipment and Operating Practices Division. Dr. John Tunna is the Director of Research and Development. Mr. Karl Alexy is the Staff Director of the Hazardous Materials Division in the FRA Office of Railroad Safety.

\section{REFERENCES}

1. Code of Federal Regulations, Title 49 - Transportation, Appendix A to Part 179 - Procedures for Tank-Head Puncture-Resistance Test, Pipeline and Hazardous Materials Safety Administration, January 2015.

2. Pipeline and Hazardous Materials Safety Administration, "Hazardous Materials: Enhanced Tank Car Standards and Operational Controls for High Hazard Flammable Trains," PHMSA-2012-0082, May 2015

https://www.fra.dot.gov/Elib/Document/14508

3. http://www.merriam-webster.com/dictionary/analytics

4. McKeighan, P.C., "Mechanical Properties of Tank Cars Steels Retired from the Fleet," Southwest Research Institute Final Report to Volpe Center, August 2008. http://ntlsearch.bts.gov/tris/record/ntl/47510.html

5. Yu, H., et al., "Analysis of Impact Energy to Fracture Unnotched Charpy Specimens Made from Railroad Tank Car Steel," Proceedings of the 2007 ASME Rail Transportation Division Fall Technical Conference, RTDF2007-46038, September 2007. http://ntlsearch.bts.gov/tris/record/ntl/47518.html

6. Tang, Y.H., et al., "Analyses of Full-Scale Tank Car Shell Impact Tests," Proceedings of the 2007 ASME Rail Transportation Division Fall Technical Conference, RTDF2007-46010, September 2007. http://ntlsearch.bts.gov/tris/record/ntl/47515.html

7. Tang, Y.H., et al., "Analysis of Railroad Tank Car Shell Impacts Using Finite Element Method," Proceedings of the 2008 IEEE/ASME Joint Rail Conference, JRC2008-63014, April 2008.

http://ntlsearch.bts.gov/tris/record/ntl/47391.html

8. Tang, Y.H., et al., "Finite Element Analyses of Railroad Tank Car Head Impacts," Proceedings of the 2008 ASME Rail Transportation Division Fall Technical Conference, RTDF2008-74022, September 2008.

http://ntlsearch.bts.gov/tris/record/ntl/47512.html

9. Yu, H., et al., "Modeling the Effect of Fluid-Structure Interaction on the Impact Dynamics of Pressurized Tank Cars," Proceedings of the 2009 ASME International 
Mechanical Engineering Congress and Exposition, IMECE2009-11926, November 2009.

http://ntlsearch.bts.gov/tris/record/ntl/43028.html

10. Kirkpatrick, S.W., "Detailed Puncture Analyses of Tank Cars: Analyses of Different Impactor Threats and Impact Conditions," Final Report DOT/FRA/ORD-13/17, March 2013. http://www.fra.dot.gov/eLib/details/L04420

11. Hou, G., Wang, J., and Layton, A., "Numerical Methods for Fluid-Structure Interaction - A Review," Communications in Computational Physics 12, August 2012, pp. 337-377. http://www.global-sci.com/openaccess/v12_337.pdf

12. Shang, J.C., and Everett, J.E., "Impact Vulnerability of Tank Car Heads," Shock and Vibration Bulletin 42, 197 210, 1972.

13. Belport, S.M., "Evaluation of the Puncture Resistance for Stainless Steel and Carbon Steel Tank Heads," AAR report No. P-93-114, June 1993.

14. Jeong, D.Y., Tang, Y.H., and Perlman, A.B., "Evaluation of Semi-Empirical Analyses for Railroad Tank Car Puncture Velocity, Part I: Correlations with Experimental Data," Final Report DOT/FRA/ORD-01/21.1, November 2001. http://ntlsearch.bts.gov/tris/record/ntl/12864.html

15. Jeong, D.Y., Tang, Y.H., and Perlman, A.B., "Evaluation of Semi-Empirical Analyses for Railroad Tank Car Puncture Velocity, Part II: Correlations with Engineering Analyses," Final Report DOT/FRA/ORD-01/21.2, November 2001. http://ntlsearch.bts.gov/tris/record/ntl/19854.html

16. Jeong, D.Y., Tang, Y.H, and Perlman, A.B., "SemiAnalytical Approach to Estimate Railroad Tank Car Shell Puncture," Proceedings of the ASME/ASCE/IEEE 2011 Joint Rail Conference, JRC2011-56028, March 2011. http://ntlsearch.bts.gov/tris/record/ntl/37909.html

17. Anderson, T.L., and Kirkpatrick, S.W., "Quantifying the Enhanced Puncture Resistance in Railroad Tank Cars
Carrying Hazardous Materials, Phase I: Preliminary Study," Structural Reliability Technology, Inc. Report Prepared for The Chlorine Institute, August 2006.

18. Anderson, T.L., Kirkpatrick, S.W., and McKeighan, P.C., "Quantifying the Enhanced Puncture Resistance in Railroad Tank Cars Carrying Hazardous Materials, Phase II: Development and Validation of a Puncture Resistance Evaluation Methodology," Quest Reliability LLC Report Prepared for The Chlorine Institute, December 2007. https://www.fra.dot.gov/eLib/Details/L02526

19. Treichel, T.T., et al., "Safety Performance of Tank Cars in Accidents: Probabilities of Lading Loss," RSI-AAR Tank Car Safety Research and Test Project Report RA 05-02, January 2006.

20. Jeong, D.Y., "Probabilistic Approach to Conditional Probability of Release of Hazardous Materials from Railroad Tank Cars during Accidents," Proceedings of the 2009 ASME International Mechanical Engineering Congress and Exposition, IMECE2009-10872, November 2009. http://ntlsearch.bts.gov/tris/record/ntl/43027.html

21. Palmer, A., Neilson, A., and Sivadasan, S., "Impact resistance of pipelines and loss-of-containment limit state," Journal of Pipeline Integrity 2, 2003, pp. 231-240.

22. Faber, M.H., "On the treatment of uncertainties and probabilities in engineering decision analysis," Journal of Offshore Mechanics and Arctic Engineering 127, August 2005, pp. 243-248.

23. Bing, A., et al., "Risk Evaluation Framework and Selected Metrics for Tank Cars Carrying Hazardous Materials," Final Report, DOT/FRA/ORD-15/07, May 2015. https://www.fra.dot.gov/eLib/details/L16361\#p1_z5_gD_IR T_y2015_m5 